\title{
Phenethyl isothiocyanate induces apoptosis and inhibits cell proliferation and invasion in Hep-2 laryngeal cancer cells
}

\author{
MENG-YUAN DAI ${ }^{1 *}$, YAN WANG $^{1 *}$, CHEN CHEN $^{1,2}$, FEN LI $^{2}$, BO-KUI XIAO ${ }^{2}$, \\ SHI-MING $\mathrm{CHEN}^{1,2}$ and ZE-ZHANG TAO ${ }^{1,2}$ \\ ${ }^{1}$ Department of Otolaryngology-Head and Neck Surgery, Renmin Hospital of Wuhan University; \\ ${ }^{2}$ Otolaryngology-Head and Neck Surgery Institute, Medical School of Wuhan University, Wuhan, Hubei 430060, P.R. China
}

Received October 16, 2015; Accepted November 22, 2015

DOI: $10.3892 /$ or.2016.4689

\begin{abstract}
The dietary compound phenethyl isothiocyanate (PEITC), an important tumoricidal component found in cruciferous vegetables, exhibits strong anticancer and chemopreventive effects in a variety of tumors. However, its role in human laryngeal cancer is unclear. The aim of the present study was to investigate whether PEITC exhibits anticancer properties in human laryngeal carcinoma Hep-2 cells in vitro and to identify the potential molecular mechanisms. The results showed that treatment of Hep-2 cells with PEITC significantly inhibited cell proliferation in a dose- and timedependent manner, promoted apoptosis with concurrent G2/M cell cycle arrest and inhibited cell invasion in a dose-dependent manner. These effects were accompanied by significant alterations in the expression levels of key proteins associated with pro-survival signaling pathways, including PI3K, Akt, ERK, $\mathrm{NF}-\kappa \mathrm{B}, \mathrm{Bcl}, \mathrm{Bax}$, cyclin B, CDK4 and CDK6. Importantly, these effects were not reflected in $16 \mathrm{HBE}$ normal human bronchial epithelial cells, suggesting a safe range of treatment concentrations between 0 and $10 \mu \mathrm{M}$ PEITC. In summary, PEITC exhibited significant anticancer effects against human laryngeal cancer cells in vitro with low toxicological impact on normal bronchial epithelial cells. This was achieved through dysregulation of key proteins involved in the occurrence and development of tumors, thereby offering a valuable contribution to future strategies for the treatment and screening of patients with laryngocarcinoma.
\end{abstract}

Correspondence to: Professor Ze-Zhang Tao or Professor Shi-Ming Chen, Department of Otolaryngology-Head and Neck Surgery, Renmin Hospital of Wuhan University, Wuhan, Hubei 430060, P.R. China

E-mail: taozezhang@hotmail.com

E-mail: shimingchen0468@163.com

${ }^{*}$ Contributed equally

Key words: phenethyl isothiocyanate, laryngeal carcinoma, Hep-2, anticancer, toxicity

\section{Introduction}

Laryngeal squamous cell carcinoma (LSCC) is one of the most malignant forms of head and neck cancers and is particularly prevalent in Asia and South China. Currently, surgery or total laryngectomy, followed by radiotherapy or chemotherapy, is the primary treatment strategy for LSCC. However, the prognosis of patients with LSCC is poor due to the advanced stage at which the disease typically presents. Associated complications, such as trachyphonia, dysphagia, dyspnea and coughing, can seriously affect the quality of life of patients (1). Due to the high mortality rate and morbidity associated with LSCC, effective treatment remains a considerable clinical challenge (2). Therefore, new and effective preventive and therapeutic strategies are urgently needed.

Epidemiological and case-control studies have indicated a strong correlation between the consumption of certain vegetables and the decreased risk of carcinogenesis $(3,4)$. Recently, it has been suggested that phenethyl isothiocyanate (PEITC), an important tumoricidal component found in cruciferous vegetables such as broccoli and cauliflower may possess anticancer properties against various malignancies, including breast, colon and prostate cancers (5-9). Several mechanisms have been proposed for these actions, including the generation of reactive oxygen species and initiation of cell cycle arrest (10). However, the role of PEITC in human laryngocarcinoma cells remains largely unknown.

The primary aim of the present study was to determine the actions and potential mechanisms of PEITC in laryngocarcinoma, including LSCC, by studying its effects on proliferation, apoptosis, cell cycle and metastasis in human laryngeal cancer Hep-2 and normal bronchial epithelial 16HBE cells in vitro in order to provide a basis for targeted therapies and drug screening in patients with LSCC.

\section{Materials and methods}

Cell lines, reagents and kits. Human laryngeal cancer cell line Hep-2 and human normal bronchial epithelial cell line 16HBE were cryopreserved in our laboratory and stored in liquid nitrogen. PEITC was obtained from Sigma-Aldrich (St. Louis, MO, USA). Other reagents included dimethylsulfoxide (DMSO) (Sigma-Aldrich), fetal bovine serum (FBS; HyClone, 
Logan, UT, USA), RPMI-1640 medium and 0.25\% trypsin solution (Invitrogen, Carlsbad, CA, USA). Experimental equipment included Cell Counting Kit-8 (CCK8; Dongji, Japan), Annexin V-FITC/propidium iodide (PI) apoptosis detection kit, PI cell cycle analysis kit (both from Lianke, China), TUNEL apoptosis detection kit (Roche, Indianapolis, IN, USA) and a Transwell insert chamber coated with Matrigel (BD Biosciences, San Jose, CA, USA). Primary antibodies against Bcl-2, Bax, Bcl-xl, PI3K class III, PI3K p110 $\alpha$, PI3K p110 $\beta$, p-Akt, p-c-Raf, p-NF- $\mathrm{B}$-p65, p-ERK, cyclin D1, CDK4 and CDK6 and GAPDH were all purchased from Cell Signaling Technology (Danvers, MA, USA).

Cell culture and treatments. Hep-2 and 16HBE cells were cultured in RPMI-1640 medium supplemented with $10 \%$ FBS and $20 \mu \mathrm{g} / \mathrm{ml}$ antibiotics (ampicillin and kanamycin) at $37^{\circ} \mathrm{C}$ in a humidified atmosphere of $5 \% \mathrm{CO}_{2}$. The cells were harvested in their logarithmic growth phase by trypsinization for use in the experiments. The cells were seeded in 96-well plates at a density of $1 \times 10^{3}$ cells/well for normal culture. They were divided into groups in 6-well plates and treated by adding PEITC to give the following final concentrations: Hep- 2 cells, $0,2.5,5,7.5$ and $10 \mu \mathrm{M}$; and $16 \mathrm{HBE}$ cells, $0,5,10,15$ and $20 \mu \mathrm{M}$. All experiments were performed at least three times.

Cell proliferation assay. Hep-2 and 16HBE cells were treated with PEITC as described above, for $0,24,48$ and $72 \mathrm{~h}$ before being incubated with $10 \mu \mathrm{lCCK}-8$ for $1 \mathrm{~h}$ at $37^{\circ} \mathrm{C}$. DMSO was used as a negative control. Six repeats were prepared for each treatment group. Absorbances were detected at $450 \mathrm{~nm}$, and $\mathrm{IC}_{50}$ values were calculated by sigmoidal dose-response nonlinear regression analysis using GraphPad Prism software version 5.04 (GraphPad Software, San Diego, CA, USA).

Flow cytometry with Annexin V-FITC for the detection of apoptosis. After being treated with PEITC for $24 \mathrm{~h}$ as described above, the cells were harvested by trypsinization, centrifuged and washed in cold phosphate-buffered saline (PBS). The cells were then stained with $5 \mu$ l Annexin V-FITC solution and $10 \mu \mathrm{l}$ of PI solution for $15 \mathrm{~min}$. Stained cells were analyzed using a FACSCanto ${ }^{\mathrm{TM}}$ II spectrometer (BD Biosciences). Data were analyzed using FlowJo version 7.6.5 software (FlowJo LLC, Ashland, OR, USA).

Flow cytometry with PI for cell cycle analysis. After treatment with PEITC for $24 \mathrm{~h}$ as described above, the cells were fixed in $70 \%$ ethanol overnight. The cells were centrifuged and the cell pellets were recovered and resuspended in $1 \mathrm{mg} / \mathrm{ml}$ RNase and $20 \mu 10.5 \%$ Triton X-100. The cells were then incubated with $5 \mu \mathrm{l}$ of $1 \mathrm{mg} / \mathrm{ml}$ PI solution for $30 \mathrm{~min}$ at room temperature. Cell cycle distribution was analyzed using FlowJo software, and the percentages of cells at each phase of the cell cycle were calculated.

TUNEL assay for detection of apoptosis. Hep-2 cells were treated with PEITC for $24 \mathrm{~h}$ as described above, and then washed in PBS, air dried and fixed with freshly prepared $4 \%$ paraformaldehyde. Terminal deoxynucleotidyl transferase dUTP nick end labeling (TUNEL) was performed according to the manufacturer's protocol (Roche). In brief, the cells were incubated with TUNEL reaction mixture for $1 \mathrm{~h}$ at $37^{\circ} \mathrm{C}$. The slides were washed in PBS and stained with 4',6-diamidino2-phenylindole (DAPI) before being viewed under microscopy. Six fields were randomly selected from every sample, and 100 cells were randomly selected from every field. The apoptotic rate was calculated as the total number of apoptotic cells $/ 100 \times 100 \%$.

Transwell invasion assay. Cell invasion assays were performed using Transwell migration chambers with Matrigel-coated inserts (BD Biosciences) according to the manufacturer's protocol. In brief, $1 \times 10^{5} \mathrm{Hep}-2$ cells were suspended in $200 \mathrm{ml}$ serum-free RPMI-1640 medium and treated with PEITC for $48 \mathrm{~h}$ as described above. The cells were seeded in Matrigel-coated inserts in the upper chamber; the lower chamber contained RPMI-1640 medium with $10 \%$ FBS as the chemoattractant. After incubation for $48 \mathrm{~h}$ at $37^{\circ} \mathrm{C}$ in a humidified atmosphere of $5 \% \mathrm{CO}_{2}$, any cells that had not penetrated the membrane were removed using cotton swabs; the cells that had successfully migrated to the bottom surfaces of the membranes were fixed with $4 \%$ polyoxymethylene and stained with $0.1 \%$ crystal violet for $20 \mathrm{~min}$. They were counted under a microscope at a magnification of $\mathrm{x} 100$.

Western blotting. Hep-2 cells were treated with PEITC for $24 \mathrm{~h}$ as described above. Total cell lysates were extracted from the harvested cells using complete protease inhibitor 'cocktail' (Roche) and $2 \mathrm{mM}$ dithiothreitol (DTT). The proteins were resolved by $12 \%$ SDS-PAGE and transferred to polyvinylidene fluoride (PVDF) membranes before being incubated with the following primary antibodies: anti-Bcl-2, anti-Bax, antiBcl-xl, anti-PI3K class III, anti-PI3K p110 $\alpha$, anti-PI3K p110 $\beta$, anti-p-Akt, anti-p-PDK1, anti-GSK3- $\beta$, anti-p-c-Raf, anti-pNF- $\mathrm{B}$-p65, anti-p-ERK, anti-cyclin B1, anti-CDK4 and anti-CDK6. GAPDH was used as an internal control. After being stained with their respective secondary antibodies, the proteins were detected by Odyssey infrared imaging (LI-COR Biosciences, Lincoln, NE, USA).

Statistical analysis. Statistical analyses were carried out by one-way ANOVA using SPSS statistical software version 16.0 (SPSS, Inc., Chicago, IL, USA). All data are expressed as mean \pm SD. P-values $<0.05$ were considered to indicate a statistically significant result.

\section{Results}

Effects of PEITC treatment on the viability of the Hep-2 and $16 H B E$ cells. The influence of PEITC treatment on proliferation in human Hep-2 laryngeal tumor cells and normal 16HBE bronchial epithelial cells was determined by CCK-8 assays. The results showed that PEITC exerted profound dose- and time-dependent antiproliferative effects on the growth of Hep- 2 cells when administered between 0 and $10 \mu \mathrm{M}$ for treatment times from 0-72 h (Fig. 1A). The inhibitory efficiency at $10 \mu \mathrm{M}$ PEITC in Hep- 2 cells 24 h post-treatment exceeded $52 \%$. In contrast, the same treatment conditions had little effect on the proliferation of the 16HBE cells (Fig. 1B). These results confirmed that Hep-2 tumor cells exhibited greater sensitivity to PEITC than normal 16HBE bronchial epithelial cells. 

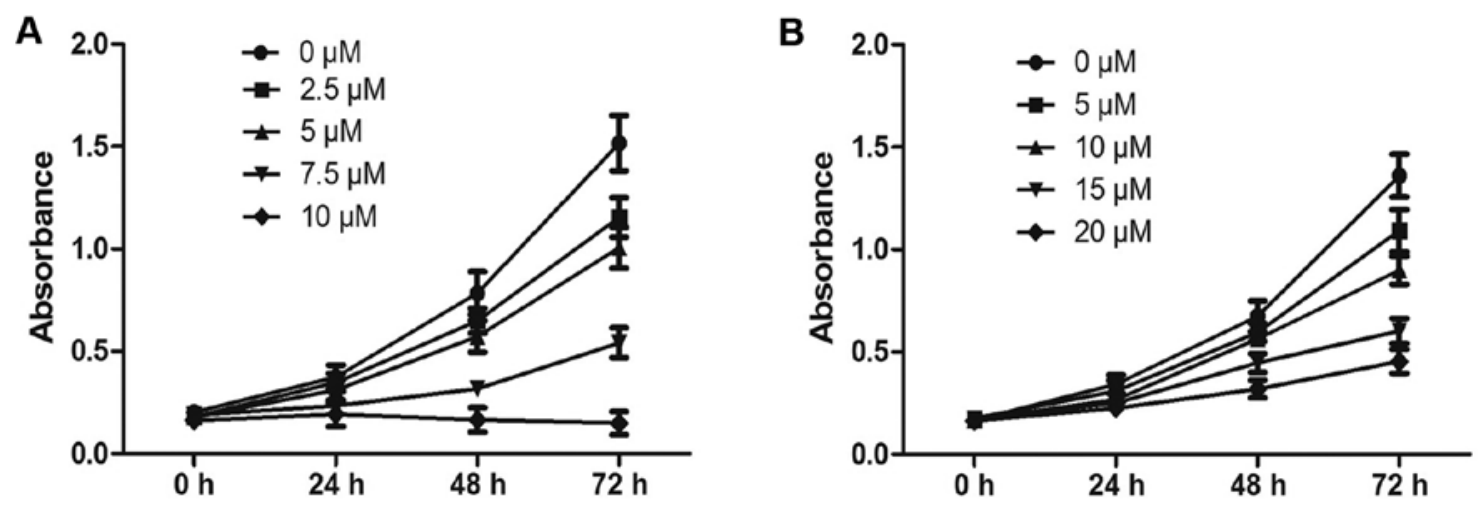

Figure 1. Viability of Hep-2 human laryngeal tumor cells and 16HBE human bronchial epithelial cells following treatment with phenethyl isothiocyanate (PEITC). (A) The results from the CCK-8 assays showed that proliferation was significantly inhibited in the Hep-2 cells in a dose- and time-dependent manner. (B) However, proliferation was not significantly inhibited in the $16 \mathrm{HBE}$ cells at concentrations $<10 \mu \mathrm{M}$ PEITC and remained comparatively low up to a concentration of $20 \mu \mathrm{M}$ PEITC. The data represent three independent experiments; error bars represent SD (ANOVA).

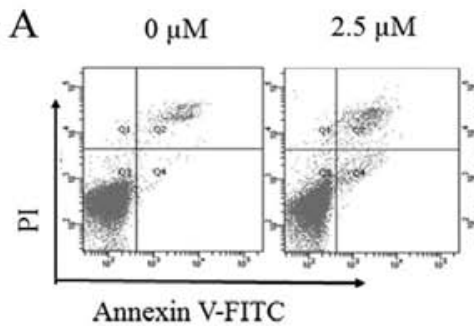

$\mathrm{B}$

$$
\text { B } \quad 0 \mu \mathrm{M}
$$

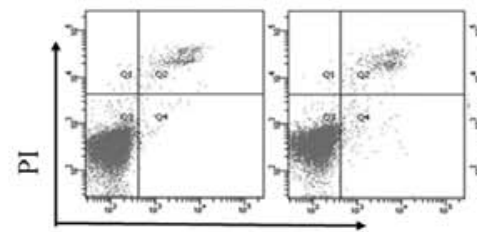

Annexin V-FITC
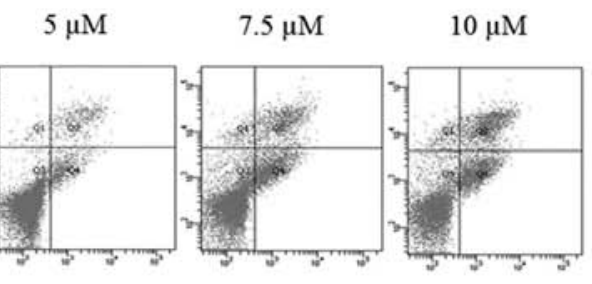

$10 \mu \mathrm{M}$
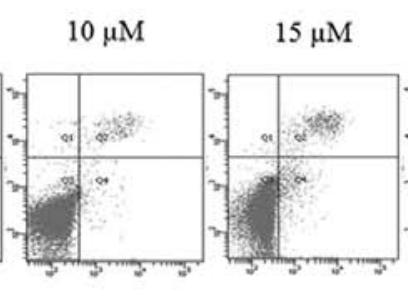

$20 \mu \mathrm{M}$

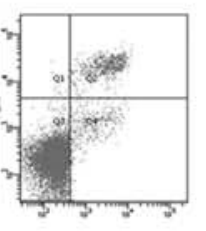

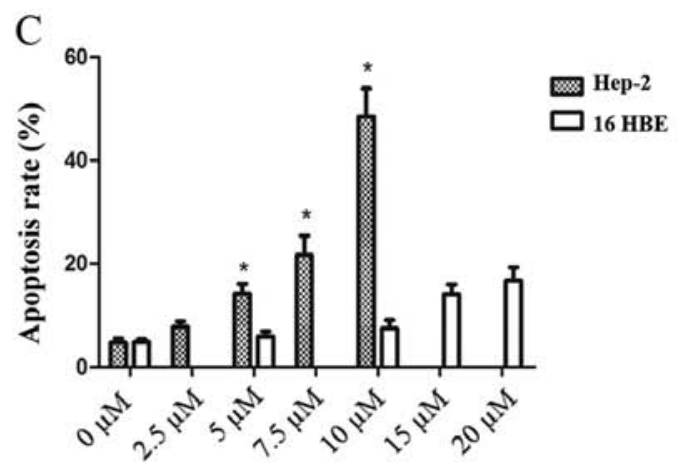

Figure 2. Annexin V-FITC flow cytometric analyses of apoptosis in Hep-2 and 16HBE cell lines treated with phenethyl isothiocyanate (PEITC). (A) The levels of both early $\left(\mathrm{FITC}^{+} / \mathrm{PI}\right)$ and late apoptotic cells $\left(\mathrm{FITC}^{+} / \mathrm{PI}^{+}\right)$clearly increased in the Hep-2 cells with increasing concentrations of PEITC. (B) There was little change in the corresponding levels of apoptotic cells in the 16HBE cells. (C) The percentages of apoptotic cells were significantly increased in Hep-2 cells at concentrations $\leq 10 \mu \mathrm{M}$ PEITC in a dose-dependent manner; whereas there was little change in the percentages of 16HBE cells up to $20 \mu \mathrm{M}$ PEITC. The data represent three independent experiments; error bars represent SD (ANOVA). P-values are given relative to $0 \mu \mathrm{M}$ PEITC, ${ }^{*} \mathrm{P}<0.05$ in Hep-2 cells; ${ }^{~} \mathrm{P}<0.05$ in $16 \mathrm{HBE}$ cells.

Effects of PEITC on apoptosis in the Hep-2 and 16HBE cells. To further explore the effects of PEITC treatment on laryngeal tumor cells, the levels of apoptosis in the Hep-2 and 16HBE cells were determined by Annexin V-FITC/PI double-staining flow cytometry after treatment with various concentrations of PEITC for $24 \mathrm{~h}$. The results demonstrated that the percentages of both early (FITC $\left.{ }^{+} / \mathrm{PI}^{-}\right)$and late apoptotic Hep-2 cells $\left(\mathrm{FITC}^{+} / \mathrm{PI}^{+}\right)$gradually increased with increasing concentrations of PEITC in a dose-dependent manner (Fig. 2A). At $10 \mu \mathrm{M}$ PEITC, the percentages of apoptotic cells after $24 \mathrm{~h}$ treatment were 48.5 and $7.5 \%$ in the Hep-2 and 16HBE cells, respectively (Fig. 2C). In addition, the levels of apoptosis in the $16 \mathrm{HBE}$ cells remained comparatively low at higher concentrations of PEITC, with only 14.1 and $16.7 \%$ apoptotic cells at 15 and $20 \mu \mathrm{M}$ PEITC, respectively (Fig. 2B). These results demonstrated that normal 16HBE bronchial cells exhibited higher tolerance to PEITC treatment than the Hep-2 tumor cells. In summary, PEITC appeared effective in inducing apoptosis in laryngeal cancer cells between 0 and $10 \mu \mathrm{M}$ PEITC in vitro while having little or no toxicological impact on normal non-tumorous bronchial cells.

Effects of PEITC on cell cycle arrest in the Hep-2 cells. To investigate the effects of PEITC treatments on laryngocarcinoma in greater detail, flow cytometric analysis with PI single-staining was used to examine cell cycle distribution in the Hep-2 cells following a 24-h treatment with increasing concentrations of PEITC. As shown in Fig. 3, the proportion of cells in the G0/G1 phase decreased from 59.13 to $41.65 \%$ as PEITC $(\mathrm{P}<0.05)$ concentrations increased from $0-10 \mu \mathrm{M}$; whereas the corresponding proportion of $\mathrm{G} 2 / \mathrm{M}$ phase cells significantly increased from 6.93 to $22.27 \%(\mathrm{P}<0.05)$; and the proportion of $\mathrm{S}$ phase cells increased marginally from 28.25 to $32.49 \%$. These results demonstrated that PEITC has the 


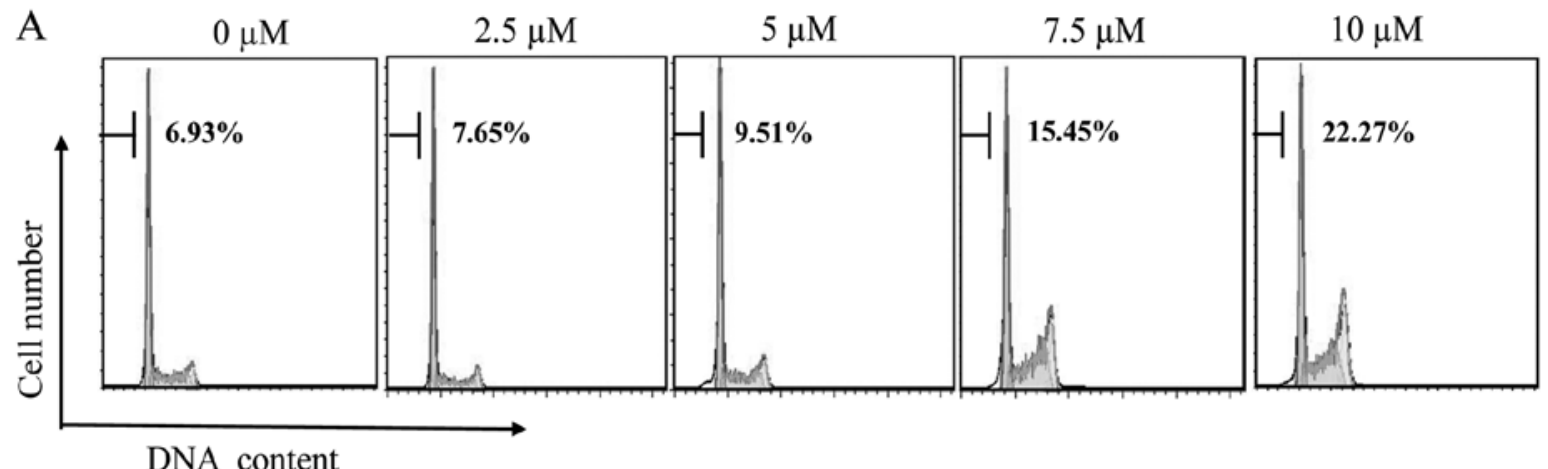

B

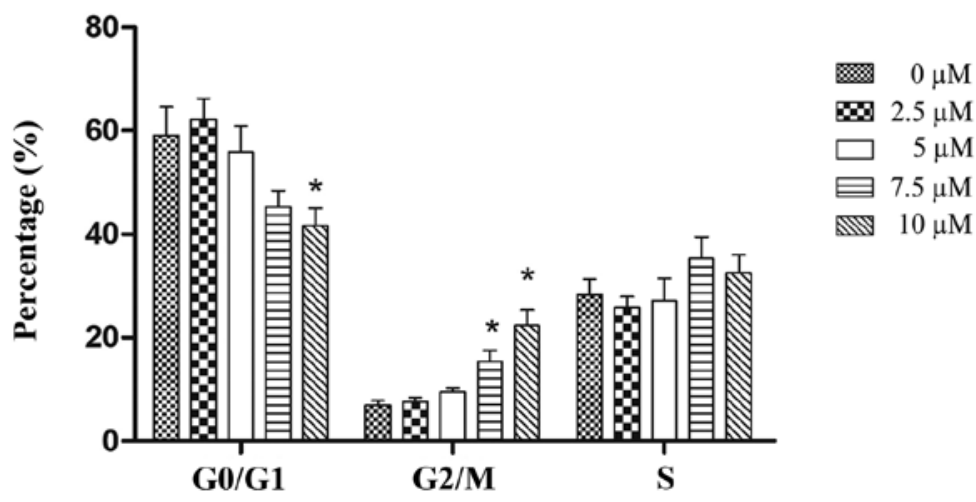

Figure 3. Flow cytometric analysis of cell cycle distribution in Hep-2 cell lines following treatment with PEITC. (A) The proportion of cells in the G2/M phase increased in the Hep-2 cells as the concentration of PEITC increased. (B) Significant concurrent decreases were noted in the percentages of cells in the G0/ G1 phase and S phase while the percentages of $\mathrm{G} 2 / \mathrm{M}$ phase cells increased during treatment. The data represent three independent experiments; error bars represent $\mathrm{SD}$ (ANOVA). ${ }^{*} \mathrm{P}<0.05$ compared to values at $0 \mu \mathrm{M}$ PEITC.

greatest influence in promoting cell cycle arrest in Hep-2 cells at the $\mathrm{G} 2 / \mathrm{M}$ phase.

TUNEL detection of cell apoptosis in the Hep-2 cells. TUNEL assays were performed to verify the flow cytometric results and to further explore the pro-apoptotic effects of PEITC treatment on the laryngeal tumor cells. The micrographs were analyzed by fluorescence microscopy $24 \mathrm{~h}$ post-treatment and showed that the mean percentages of apoptotic increased from $1.32 \pm 2.57$ at a concentration of 0 PEITC to $4.80 \pm 1.77$, $8.98 \pm 4.41,19.50 \pm 1.58$ and $44.23 \pm 2.31 \%$ at concentrations of $2.5,5,7.5$ and $10 \mu \mathrm{M}$ PEITC, respectively. These results confirmed that PEITC induced apoptosis in the Hep- 2 cells in a dose-dependent manner (Fig. 4).

Effects of PEITC treatment on cell invasion in the Hep-2 cells. A Transwell assay was performed to determine whether PEITC influences the invasiveness of Hep-2 laryngeal cancer cells. Following treatment with $0-10 \mu \mathrm{M}$ PEITC for $48 \mathrm{~h}$, the data clearly demonstrated that PEITC suppressed the invasive ability of the Hep-2 cells in a dose-dependent manner (Fig. 5). The effects were most significant at concentrations $\geq 5 \mu \mathrm{M}$ PEITC $(\mathrm{P}<0.05)$.

Effects of PEITC treatment on protein expression levels associated with proliferation, apoptosis and cell cycle signaling pathways. Having demonstrated that PEITC treatment could have significant effects on proliferation, apoptosis, cell cycle distribution and invasion in Hep-2 cells, it was necessary to explore the potential mechanisms. Therefore, western blotting was performed to identify changes in the expression levels of regulatory proteins involved in key signaling pathways related to the occurrence and development of laryngocarcinoma. The pathways of interest included proliferation: PI3K, Akt, NF- $\kappa \mathrm{B}$ and ERK; apoptosis: Bcl-2, Bcl-xl and Bax; and cell cycle progression: GSK3- $\beta$, cyclin B1, CDK4 and CDK6. Qualitative analyses showed that as the PEITC concentration increased from 0 to $10 \mu \mathrm{M}$, the expression levels of PI3K class III, PI3K p110 $\alpha$, PI3K p110 $\beta$, p-Akt, p-PDK1, GSK3- $\beta$, p-NF-кB-p65, p-c-Raf, p-ERK, Bcl-2, Bcl-xl, cyclin B1, CDK4 and CDK6 were downregulated $24 \mathrm{~h}$ post-treatment and Bax was upregulated, whereas t-Akt, t-NF- $\kappa \mathrm{B}-\mathrm{p} 65$ and $\mathrm{t}-\mathrm{ERK}$ protein expression remained unchanged as the PEITC concentration increased (Fig. 6).

\section{Discussion}

Several studies have identified PEITC, a major active constituent in cruciferous vegetables, as a potential anticancer agent in various types of malignancies, including breast, colon and prostate carcinomas (7-9). However, its actions in laryngocarcinoma, including LSCC, remain largely unknown. Therefore the purpose of the present study was to explore its actions and potential mechanisms in human Hep-2 laryngeal tumor cells and normal $16 \mathrm{HBE}$ bronchial epithelial cells.

Our findings demonstrated that treatment with PEITC significantly suppressed proliferation, induced apoptosis, promoted $\mathrm{G} 2 / \mathrm{M}$ cell cycle arrest and inhibited invasion and 
A

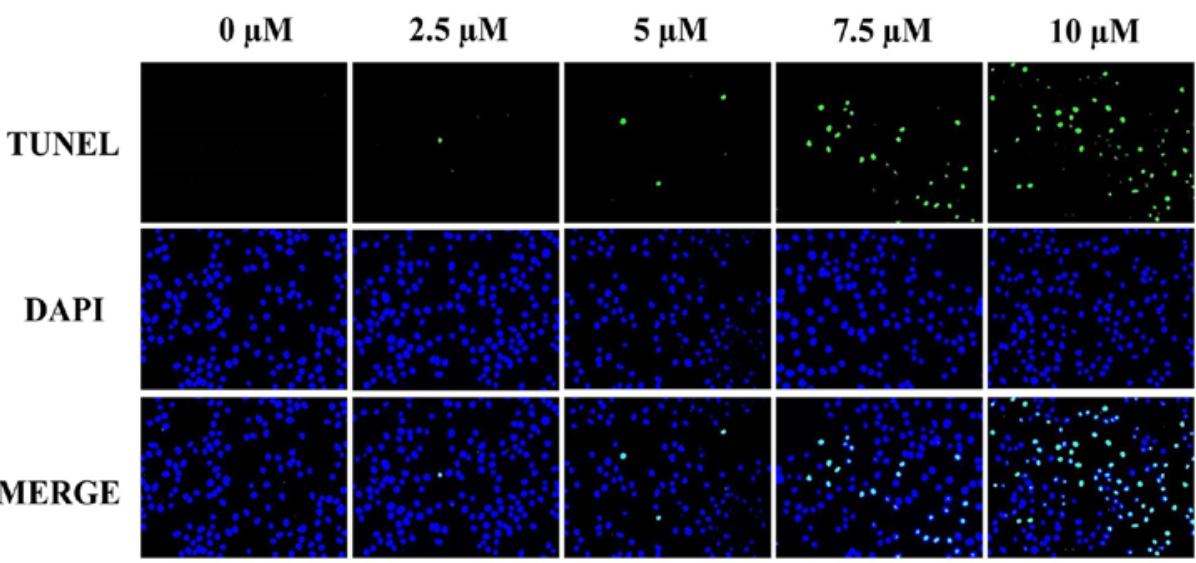

B

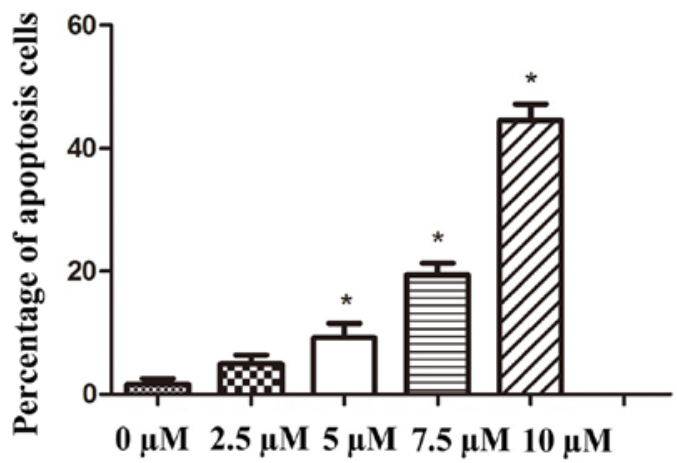

Figure 4. Detection of cell apoptosis in the Hep-2 laryngeal cancer cells by TUNEL assays. (A) Apoptosis in the Hep-2 cells increased as the concentrations of PEITC increased. (B) Quantification of the TUNEL results indicate that the increases in apoptotic cells were significant at concentrations $>5 \mu \mathrm{M}$ PEITC $24 \mathrm{~h}$ post-treatment. The data represent three independent experiments; error bars represent SD (ANOVA). ${ }^{*}<0.05$ relative to values at $0 \mu \mathrm{M}$ PEITC.

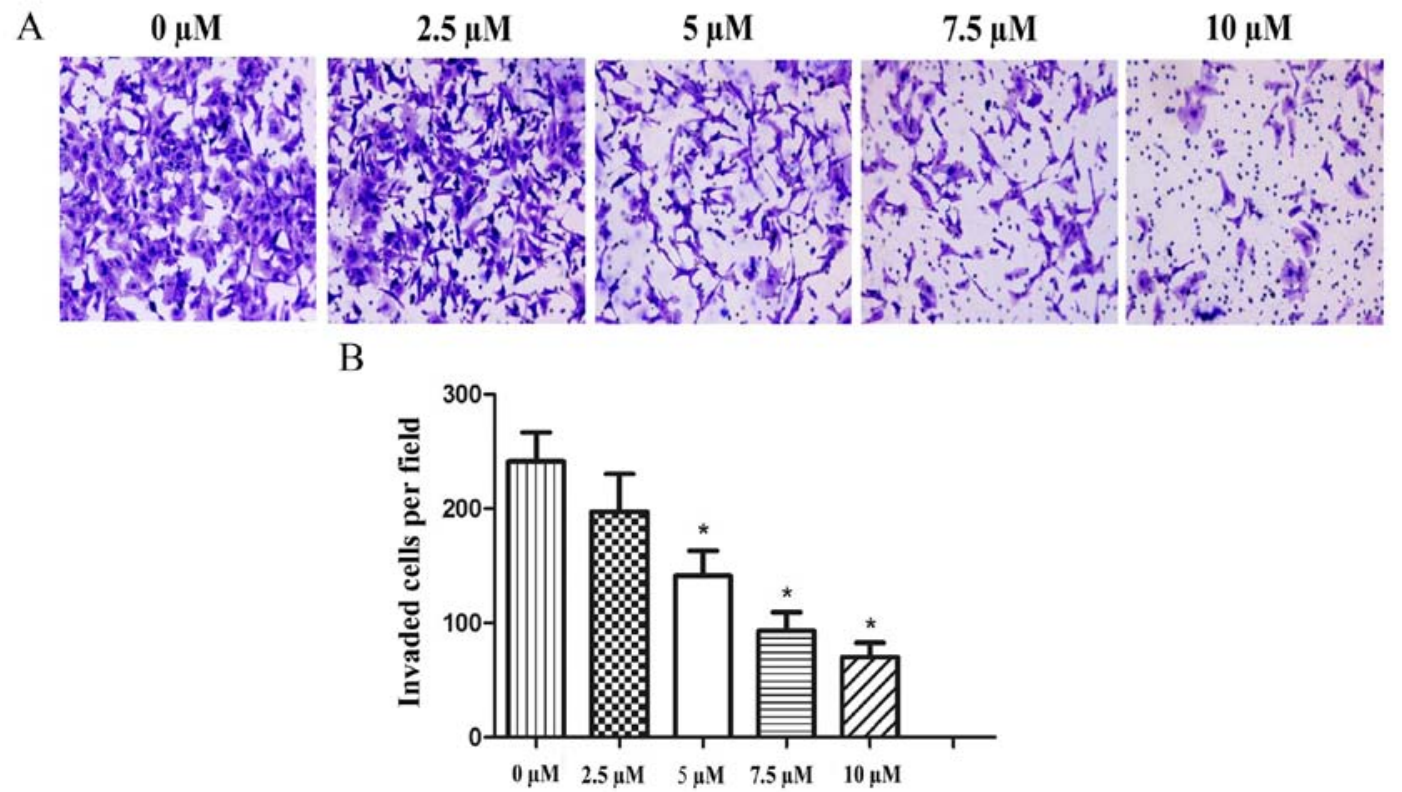

Figure 5. Transwell invasion assays of Hep-2 cells treated with PEITC. (A) A decrease in the numbers of migrating Hep-2 cells was noted following a 48-h treatment with PEITC. (B) Quantification of the cell counts at each concentration of PEITC are given in the plot, based on the mean values/field from at least five randomly selected low-power fields (magnification, $\mathrm{x} 200$ ). The data represent three independent experiments; error bars represent $\mathrm{SD}$ (ANOVA). $\mathrm{P}<0.05$ relative to values at $0 \mu \mathrm{M}$ PEITC.

thereby metastasis, in the Hep-2 cancer cells in vitro $(\mathrm{P}<0.05)$. Importantly, the results also demonstrated that treatment within a safe range of concentrations (from 0-10 $\mu \mathrm{M}$ PEITC) had little toxicological impact on normal 16HBE cells. These findings were consistent with published studies on other types of cancer (11-13); for example, Wang et al showed that treat- 

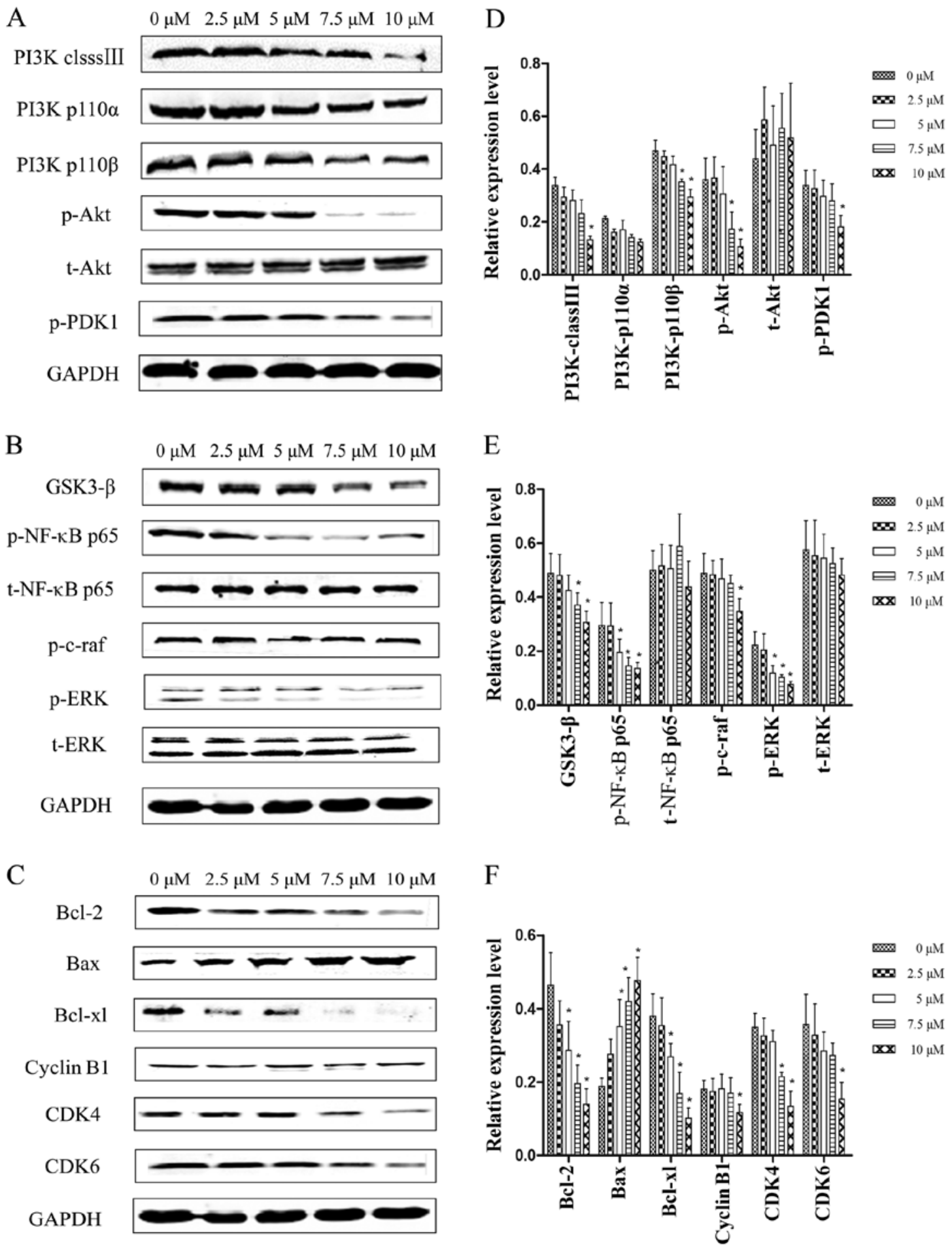

Figure 6. Western blot assays of protein expression levels in proliferation, apoptosis and cell cycle progression pathways in the Hep-2 cells treated with PEITC for $24 \mathrm{~h}$. (A) PI3K class III, PI3K p110 $\alpha$, PI3K p110 $\beta$, p-Akt, t-Akt and p-PDK1. (B) GSK3- $\beta$, p-NF-kB p65, t-NF-kB p65, p-c-Raf p-ERK and t-ERK. (C) Bcl-2, Bax, Bcl-xl, cyclin B1, CDK4 and CDK6. (D-F) Data presented are the means \pm SD. Results were normalized to GAPDH. "P<0.05 relative to values at $0 \mu \mathrm{M}$ PEITC.

ment with 5-10 $\mu \mathrm{M}$ PEITC for 8-24 h could inhibit proliferation and induce apoptosis in cervical cancer cells (14).

Our results also showed that PEITC significantly inhibited proliferation in Hep-2 cells in a time- and dose-dependent manner, and significantly promoted apoptosis and inhibited cell invasion in a dose-dependent manner $(\mathrm{P}<0.05)$. Similar observations have been reported in previous studies $(15,16)$. For example, the percentage of Hep-2 cells was reduced to $52 \%$ and the percentage of apoptotic cells was increased to $48 \% 24 \mathrm{~h}$ post-treatment with $10 \mu \mathrm{M}$ PEITC relative to the corresponding levels at $0 \mu \mathrm{M}$ PEITC $(\mathrm{P}<0.05)$. These effects were accompanied by concurrent increases in the percentages of cells at the G2/M phase, suggesting that PEITC may inhibit cell growth by inducing cell cycle arrest at the G2/M checkpoint. 
Tumorigenesis is characterized by uncontrolled cell growth and tumor formation and is associated with alterations in the expression levels of proteins involved in pro-survival signaling pathways linked to the occurrence and development of tumors (17). Furthermore, the suppression of multiple signaling pathways simultaneously has been found to have a greater anticancer impact than suppression of a single signaling pathway alone (18-20). Proteins such as PI3K, Akt, ERK and NF- $\mathrm{B}$ have been found to play key roles in the regulation of proliferation, cell cycle progression and apoptosis in LSCC (21-23). RNAi is frequently used to inhibit the expression of proteins and has proven to be important in developing effective therapeutic strategies against cancers. Using these methods, our results indicated that PEITC may target several important signaling pathways associated with apoptosis, cell growth and metastasis simultaneously, thereby enhancing its antitumor impact on laryngocarcinoma.

Metastasis and tumor cell invasion are important factors in the prognosis and recurrence of cancers. Our results showed that treatment with PEITC inhibited the invasiveness of Hep-2 cells in vitro and suggested that this effect was due in part to the suppression of ERK and NF- $\kappa \mathrm{B}$ activity. Similar findings were reported by Gupta et $\mathrm{al}$ in a mouse model of breast cancer in which the administration of PEITC suppressed development of metastasized tumors (24). However, data on the antimetastatic effects of PEITC in other forms of cancer remain scarce, and further investigations is needed to elucidate the molecular mechanisms.

Currently, surgery followed by radiotherapy or chemotherapy is the primary treatment for LSCC. However, this strategy frequently results in damage to normal surrounding tissues $(25,26)$. Consequently, there is increasing interest in identifying natural compounds with effective anticancer properties due their low toxicities (27). The results of the present study demonstrated that PEITC was effective in suppressing proliferation, invasion and inducing apoptosis in Hep-2 laryngeal cancer cells while having little toxicological impact on 16HBE normal bronchial epithelial cells, particularly within a range of $0-10 \mu \mathrm{M}$ PEITC. Although, increased levels of apoptosis were observed in 16HBE cells at higher concentrations of PEITC (up to $20 \mu \mathrm{M}$ ), these remained comparatively low relative to the levels in the Hep-2 cells. Similar observations have been reported previously. PEITC was found to inhibit mammary carcinoma tissues in a mouse model, but was well-tolerated in normal mammary glands (28); however, another study reported increased levels of aspartate aminotransferase (AST) at high doses of PEITC (100-150 mg/kg) but no change was observed at lower doses $(50 \mathrm{mg} / \mathrm{kg})$, suggesting that PEITC may cause dose-dependent toxicity in normal tissues at high treatment concentrations (29). Variations in treatment times or analytical time points between different studies may have contributed to these inconsistencies (30). Therefore, further in vivo studies are required to define the toxicity profile of PEITC in laryngocarcinoma in order to ensure that doses can be titrated accurately in a clinical setting.

In conclusion, the present study demonstrated that PEITC significantly induced antiproliferative, pro-apoptotic and antimetastatic effects in Hep-2 human laryngeal cancer cells in a time- and dose-dependent manner, while presenting little toxicological damage to normal 16HBE bronchial epithelial cells in vitro. The findings suggest that its anticancer activities resulted from its ability to inhibit several critical pro-survival pathways related to the occurrence and development of laryngocarcinoma simultaneously via dysregulation of key cell signaling proteins. In summary, PEITC may offer a valuable contribution to the development of novel therapeutic strategies for the treatment of LSCC in the future.

\section{Acknowledgements}

The present study was supported by the National Natural Science Foundation of China (grant nos. 81001214, 81172569 and 81372880).

\section{References}

1. Marioni G, Marchese-Ragona R, Cartei G, Marchese F and Staffieri A: Current opinion in diagnosis and treatment of laryngeal carcinoma. Cancer Treat Rev 32: 504-515, 2006.

2. Morshed K: Association between human papillomavirus infection and laryngeal squamous cell carcinoma. J Med Virol 82: 1017-1023, 2010.

3. Kolonel LN, Hankin JH, Whittemore AS, Wu AH, Gallagher RP, Wilkens LR, John EM, Howe GR, Dreon DM, West DW, et al: Vegetables, fruits, legumes and prostate cancer: A multiethnic case-control study. Cancer Epidemiol Biomarkers Prev 9: 795-804, 2000.

4. Hanahan D and Weinberg RA: Hallmarks of cancer: The next generation. Cell 144: 646-674, 2011.

5. Annema N, Heyworth JS, McNaughton SA, Iacopetta B and Fritschi L: Fruit and vegetable consumption and the risk of proximal colon, distal colon, and rectal cancers in a case-control study in Western Australia. J Am Diet Assoc 111: 1479-1490, 2011.

6. Gupta P, Kim B, Kim SH and Srivastava SK: Molecular targets of isothiocyanates in cancer: Recent advances. Mol Nutr Food Res 58: 1685-1707, 2014

7. Trachootham D, Zhou Y, Zhang H, Demizu Y, Chen Z, Pelicano H, Chiao PJ, Achanta G, Arlinghaus RB, Liu J, et al: Selective killing of oncogenically transformed cells through a ROS-mediated mechanism by beta-phenylethyl isothiocyanate. Cancer Cell 10: 241-252, 2006.

8. Huong D, Shim JH, Choi KH, Shin JA, Choi ES, Kim HS, Lee SJ, Kim SJ, Cho NP and Cho SD: Effect of $\beta$-phenylethyl isothiocyanate from cruciferous vegetables on growth inhibition and apoptosis of cervical cancer cells through the induction of death receptors 4 and 5. J Agric Food Chem 59: 8124-8131, 2011.

9. Sakao K, Desineni S, Hahm ER and Singh SV: Phenethyl isothiocyanate suppresses inhibitor of apoptosis family protein expression in prostate cancer cells in culture and in vivo. Prostate 72: 1104-1116, 2012.

10. Chan ATC: Nasopharyngeal carcinoma. Ann Oncol 21 (Suppl 7): vii308-vii312, 2010.

11. Xiao D, Choi S, Lee YJ and Singh SV: Role of mitogen-activated protein kinases in phenethyl isothiocyanate-induced apoptosis in human prostate cancer cells. Mol Carcinog 43: 130-140, 2005.

12. Tang NY, Huang YT, Yu CS, Ko YC, Wu SH, Ji BC, Yang JS, Yang JL, Hsia TC, Chen YY, et al: Phenethyl isothiocyanate (PEITC) promotes G2/M phase arrest via p53 expression and induces apoptosis through caspase- and mitochondria-dependent signaling pathways in human prostate cancer DU 145 cells. Anticancer Res 31: 1691-1702, 2011.

13. Huong LD, Shin JA, Choi ES, Cho NP, Kim HM, Leem DH and Cho SD: $\beta$-Phenethyl isothiocyanate induces death receptor 5 to induce apoptosis in human oral cancer cells via p38. Oral Dis 18: 513-519, 2012.

14. Wang XF, Wu DM, Li BX, Lu YJ and Yang BF: Synergistic inhibitory effect of sulforaphane and 5-fluorouracil in high and low metastasis cell lines of salivary gland adenoid cystic carcinoma. Phytother Res 23: 303-307, 2009.

15. Gupta P and Srivastava SK: Antitumor activity of phenethyl isothiocyanate in HER2-positive breast cancer models. BMC Med 10: 80, 2012. 
16. Chen G, Chen Z, Hu Y and Huang P: Inhibition of mitochondrial respiration and rapid depletion of mitochondrial glutathione by $\beta$-phenethyl isothiocyanate: Mechanisms for anti-leukemia activity. Antioxid Redox Signal 15: 2911-2921, 2011.

17. Doerfler W, Hohlweg U, Müller K, Remus R, Heller H and Hertz J: Foreign DNA integration - perturbations of the genome - oncogenesis. Ann NY Acad Sci 945: 276-288, 2001.

18. Liu SF, Wang H, Lin XC, Xiang H, Deng XY, Li W, Tang M and Cao Y: NF-kappaB inhibitors induce lytic cytotoxicity in Epstein-Barr virus-positive nasopharyngeal carcinoma cells Cell Biol Int 32: 1006-1013, 2008.

19. Jiang H, Fan D, Zhou G, Li X and Deng H: Phosphatidylinositol 3-kinase inhibitor (LY294002) induces apoptosis of human nasopharyngeal carcinoma in vitro and in vivo. J Exp Clin Cancer Res 29: 34, 2010.

20. Li SS, Tang QL, Wang SH, Wang S and Yang XM: Simultaneously targeting bcl-2 and Akt pathways sensitizes nasopharyngeal carcinoma to tumor necrosis factor-related apoptosis-inducing ligand. Cancer Biother Radiopharm 27: 88-95, 2012.

21. Chen C, Chen SM, Xu B, Chen Z, Wang F, Ren J, Xu Y, Wang Y, Xiao BK and Tao ZZ: In vivo and in vitro study on the role of 3,3'-diindolylmethane in treatment and prevention of nasopharyngeal carcinoma. Carcinogenesis 34: 1815-1821, 2013.

22. Wang YQ, Chen C, Chen Z, Xu Y, Wang Y, Xiao BK, Chen SM and Tao ZZ: Indole-3-carbinol inhibits cell proliferation and induces apoptosis in Hep-2 laryngeal cancer cells. Oncol Rep 30: 227-233, 2013.
23. Zhang X: Depression of testes-specific protease 50 (TSP50) inhibits cell proliferation and induces apoptosis in laryngocarcinoma. Tumour Biol 35: 10781-10788, 2014.

24. Gupta P, Adkins C, Lockman P and Srivastava SK: Metastasis of breast tumor cells to brain is suppressed by phenethyl isothiocyanate in a novel in vivo metastasis model. PLoS One 8: e67278, 2013.

25. Baletic N, Malicevic H, Petrovic Z, Marinkovic-Eric J and Peric A: Advantages and limitations of the autofluorescent diagnostics of the laryngeal cancer and precancerosis. Eur Arch Otorhinolaryngol 267: 925-931, 2010.

26. Siegel R, Naishadham D and Jemal A: Cancer statistics, 2013. CA Cancer J Clin 63: 11-30, 2013

27. Newman DJ and Cragg GM: Natural products as sources of new drugs over the 30 years from 1981 to 2010. J Nat Prod 75: 311-335, 2012.

28. Singh SV, Kim SH, Sehrawat A, Arlotti JA, Hahm ER, Sakao K, Beumer JH, Jankowitz RC, Chandra-Kuntal K, Lee J, et al: Biomarkers of phenethyl isothiocyanate-mediated mammary cancer chemoprevention in a clinically relevant mouse model. J Natl Cancer Inst 104: 1228-1239, 2012.

29. Manesh C and Kuttan G: Effect of naturally occurring isothiocyanates on the immune system. Immunopharmacol Immunotoxicol 25: 451-459, 2003.

30. Wang LG and Chiao JW: Prostate cancer chemopreventive activity of phenethyl isothiocyanate through epigenetic regulation (Review). Int J Oncol 37: 533-539, 2010. 